\title{
ELECTRICAL SIMULATION AND OPTIMIZATION OF PTB7:PC70BM BASED ORGANIC SOLAR CELL USING GPVDM SIMULATION SOFTWARE
}

\author{
*Khizar Jahangir', *Ghazi Aman Nowsherwan', Syed Sajjad Hussain³, Saira \\ Riaz $^{4}$, Shahzad Naseem ${ }^{5}$
}

${ }_{1,2,3,4,5}$ Centre of Excellence in Solid State Physics, University of the Punjab, Lahore, 54590, Pakistan

*Corresponding author; Email: khizerjahangir786@gmail.com, ghaziaman.pu@gmail.com
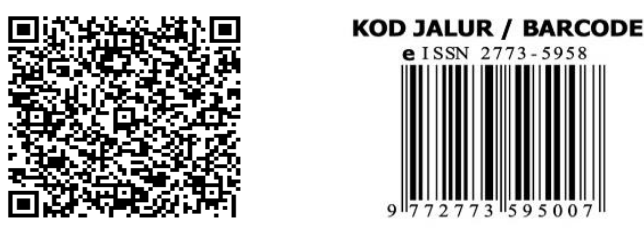

Received: 08 May 2021

Accepted: 01 August 2021

Published: 19 August 2021

Volume -2, Issue-3

Cite This: ICRRD Qual. Ind. Res. J. 2021, 2(3), 131-140

\begin{abstract}
The growing requirement for electricity and its inadequate fossil fuel supply is a global concern that's why organic solar cell (OSC) devices had more attraction in the last decades for their practical application. In this research study, GPVDM software is considered, a 3-D photovoltaic device model, used to observe the outcomes of PTB7: PC70BM based organic solar cell. The organic solar cell comprises a PTB7:PC70BM as an active layer, indium tin oxide (ITO) serving as a transparent conducting oxide, and front electrode, PEDOT: PSS for efficient transporting of holes, while Al is taken as a back metal electrode. The electrical simulation via GPVDM has been performed at different active layer thicknesses and charge carrier mobility. Furthermore, the influence of varying different HTM layers had also been studied. The optimum efficiency of OSC is obtained at $200 \mathrm{~nm}$ active layer thickness and carrier mobility of $2.46 \times 10^{6} \mathrm{~m}^{2} / \mathrm{Vs}$. The outcomes and performance of the simulated organic solar cell are compared with the practically implemented organic solar cell. This research also suggests a possible path toward the efficient implementation of organic solar cells by modifying factors that are significantly reliant on the performance and outcomes of OSCs.
\end{abstract}

Keywords: Organic, organic Solar Cells, Device Modeling, GPVDM, Simulation

\section{INTRODUCTION}

Organic solar cells are considered third-generation solar cells not of the date to be developed but on due to the material configuration. These are studied in specific areas such as DSSC, polymer-based solar cells, and somehow molecule-dependent solar cells. Organic photovoltaic devices have attracted more attention in the last decade to their applications as flexible, renewable, non-conservative energy sources. Cheap manufacturing, mechanical flexibility, lightweight, and manufacturing at low temperatures are the prime benefits of solar cells. [12]. In 1958, Calvin fabricated the first organic solar cell based on magnesium phthalocyanine (MgPc) and obtained an an open-circuit voltage of $200 \mathrm{mV}$ [3]. Later on, the energy conversion efficiency of $0.01 \%$ was obtained under the wavelength $690 \mathrm{~nm}$ based on Al/MgPc/Ag cell [4]. 
This type of solar cell was also utilized in conjugated polymers. A device with polyacetylene as the absorber layer produced an energy conversion efficiency of $0.3 \%$ and an open-circuit voltage of $0.3 \mathrm{~V}$ [5]. Tourillon. $\mathrm{G}$ et al. proposed an organic solar cell based on Al/poly (3-nethylthiophene)/Pt, which yields open-circuit voltage, fill factor (FF), and external quantum efficiency of $0.4 \mathrm{~V}, 0.3 \%$, and $0.17 \%$ [6]. Due to the low power conversion efficiencies (PCE) and low quantum efficiencies (QE) of single-layer OSC structure, scientists moved to a bilayer structure that comprises two layers amid the electrodes. Sariciftci N.S et al. fabricated a C60/MEH-PPV bi-layer OSC that yields a FF of $0.48 \%$ and PCE of $0.04 \%$ [7]. Later on, PPV/C60 based organic shows QE of $9 \%$ and the PCE of $1 \%$, along with the fill factor of $0.48 \%$ [8]. "Halls, J.J et al. fabricated an organic cell with an electron donor layer (EDL) of bis(phenethylimido) perylene on which PPV layer was deposited, gives peak value of external QE of $6 \%$ and a PCE of 1\%" [9]. Energy conversion efficiency increased dramatically after 2000 , rising from $1 \%$ to $12 \%$ by 2013 based on these core findings. The photocurrent density of organic solar cells (OSCs) generated by solar radiation is already nearing $20 \mathrm{~mA} / \mathrm{cm}^{2}$ equivalent to inorganic solar cell values [2]. In 2013 the efficiency of OSC was 2.5\%, and now, because of the current improvement, it has increased to $18 \%$ in 2020 , which in turn is because of these novel nonfullerene acceptors [10-11].

GPVDM is a free 3-D tool for the simulation of optoelectronic devices, including OLEDs, OFETs, and several other forms of solar cells like OSC, perovskite solar cells, CIGS, and CdTe, etc. "Hima et al. used GPVDM software to study the effect of some parameters on the efficiency of power conversion in planner hetero-junction solar cell based on $\mathrm{CH}_{3} \mathrm{NH}_{3} \mathrm{PbI}_{3}$ as an absorbing layer, .and achieved PCE of 12.9 \%" [12]. Afterward, Singh et al. designed a blend of an organic photovoltaic cell by GPVDM software at different charge carrier mobilities. They found the optimum efficiency of organic solar cell is obtained at $0.510 \times 10^{-6} \mathrm{~m}^{2} / \mathrm{Vs}$ value of charge carrier mobility [13]. Abdulsalam et al. modeled the perovskite-based solar cell. They analyzed that the thickness of the absorber layer has a strong influence on cells' performance and outcomes. They achieved the maximum PCE at thickness $3 \times 10^{7} \mathrm{~m}$ [14]. Rastogi et al. have employed the GPVDM simulation software to analyze the optical and electrical characteristics of OSC based on P3HT: PCBM organic ingredients. In this study, electrical stimulation was conducted at various resistance rates of the series. They concluded that the resistance of the sequence has a surprising impact on the $\mathrm{J}-\mathrm{V}$ properties of the organic solar cell [15]. Talib et al. studied the layer thickness effect on hetero-junction solar cells by using GPVDM software. They achieved the best performance at a thickness of the active layer $100 \mathrm{~nm}$ with the short-circuit current-density value of $6.60 \mathrm{~mA} / \mathrm{cm}^{2}$, while the simulation data indicates that the blend configuration gives the best outcomes at $200 \mathrm{~nm}$ [16]. Many additional softwares, such as SCAPS-1D, Silvaco TCAD, wxAMPS-1D, and COMSOL, are also useful for simulating different types of solar cells [17-24]. As OSC are considered as encouraging renewable energy sources, which are alternatives to the inorganic PV cell. In this research study, we primarily focused on different parameters of OSC that play an essential role in enhancing its performance. Also, its outcomes are compared with the experimental data reported in different literature.

\section{GPVDM DEVICE MODELING AND SIMULATION}




\section{A. Device Modeling}

The model solves all electrons, drift-diffusion holes, and carrier continuity equations in location space to describe the transport of charge carriers in the device. For the estimation of the electrostatic potential, the model also solves Poisson's equation. The Shockley-Read-Hall (SRH) formalism is used to express recombination and carrier trapping in the model, and the distribution of trap states can be freely specified [25]. The basic equations used in this model are as follows:

Gauss's Law: $\nabla_{\in_{0} \in_{r}} \cdot \nabla_{\emptyset}=\mathrm{q} \cdot(\mathrm{n}-\mathrm{p})$

Electron driving terms: $\mathrm{J}_{\mathrm{n}}=\mathrm{q} \mu_{\mathrm{e}} \mathrm{n} \nabla \mathrm{E}_{\mathrm{c}}+\mathrm{qD} \mathrm{D}_{\mathrm{n}} \nabla_{\mathrm{n}}$

Hole driving terms: $\mathrm{J}_{\mathrm{p}}=\mathrm{q} \mu_{\mathrm{h}} \mathrm{p} \nabla \mathrm{E}_{\mathrm{v}}-\mathrm{qD}_{\mathrm{p}} \nabla_{\mathrm{p}}$

Electron continuity Equation: $\nabla . \mathrm{J}_{\mathrm{n}}=\mathrm{q}\left(\mathrm{R}_{\mathrm{n}}+\mathrm{T}_{\mathrm{n}}+\frac{\partial \mathrm{n}_{\text {free }}}{\partial \mathrm{t}}\right)$

Hole continuity Equation: $\nabla . \mathrm{J}_{\mathrm{p}}=-\mathrm{q}\left(\mathrm{R}_{\mathrm{p}}+\mathrm{T}_{\mathrm{p}}+\frac{\partial \mathrm{p}_{\text {free }}}{\partial \mathrm{t}}\right)$

The adopted organic solar cell structure (Al/PTB7:PC70BM/PEDOT: PSS/ITO) is a characteristic structure in which cell comprises of an absorber layer (PTB7: PC70BM), hole transport layer (PEDOT: PSS), which assist the absorber layer in transporting charge carriers, ITO (Indium doped tin oxide) and aluminum (Al) which is serving as a front and back contact as shown in Fig.1 and Fig.2.

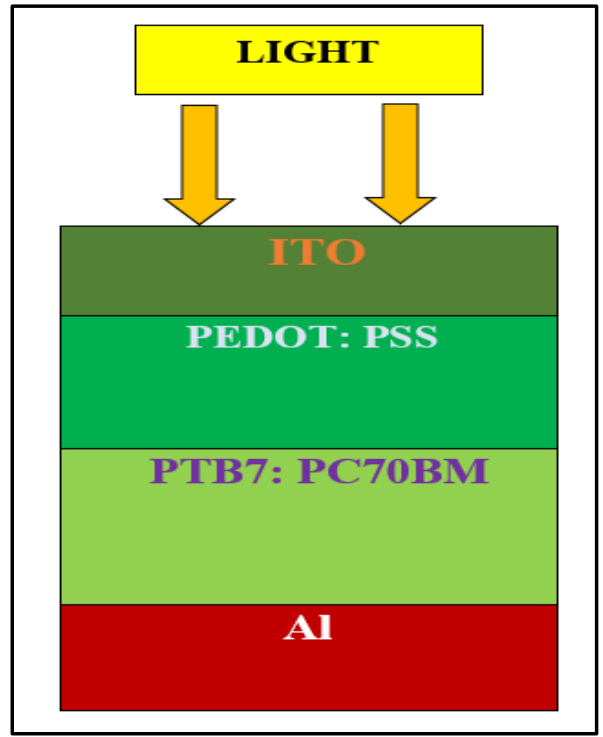

Fig. 1: Structure of developed organic solar cell (OSC)

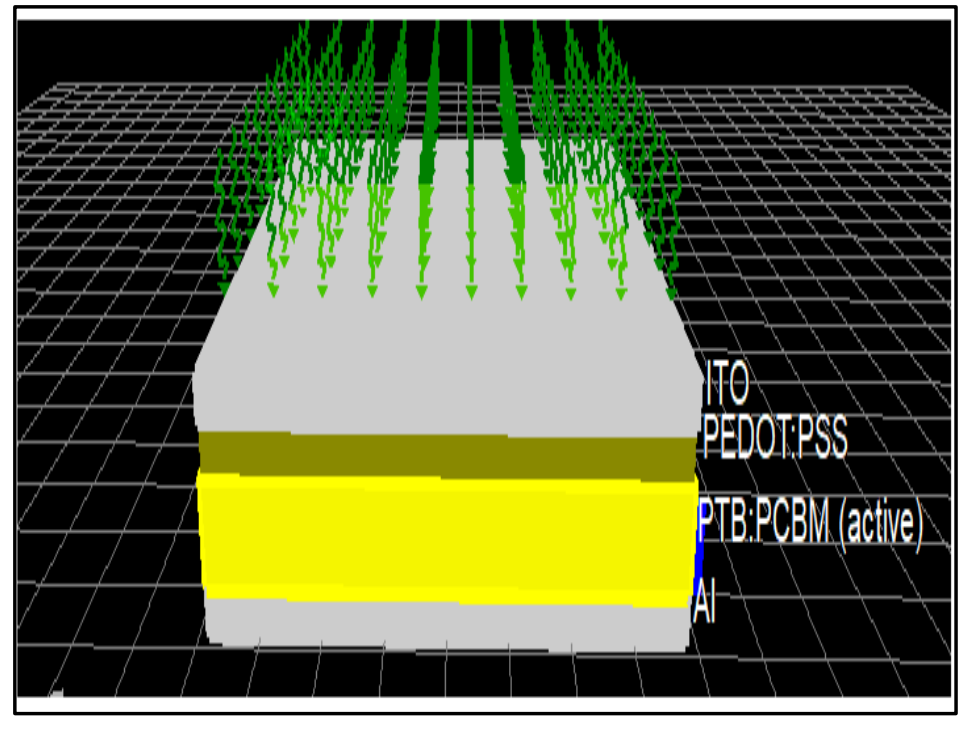

Fig. 2: Schematic view of OSC in GPVDM

\section{B. Device Simulation Parameters}

All simulation settings and parameters for the active layer in the structure were obtained from the different works published in [13-16,26]. The individual materials parameters for the absorber layer are entered in terms of traps densities, tail slope, relative permittivity, carrier mobilities, the effective density of states, and photonic bandgap. All the prime parameters elaborated in Table.1, are utilized for the simulation of the device. To make device modeling easier, the refractive index data and the absorption data were gathered from many works of literature. 
[27-30]. The operational temperature is set at $300 \mathrm{~K}$. All the simulations are run under these conditions.

Table-1: Active Layer Parameters set in simulation

\begin{tabular}{|l|l|l|}
\hline Parameters name & Values & SI units \\
\hline Electron trap density & $3.8 \times 10^{26}$ & $\mathrm{~m}^{-3} \mathrm{eV}^{-1}$ \\
\hline Hole trap density & $1.45 \times 10^{25}$ & $\mathrm{~m}^{-3} \mathrm{eV}^{-1}$ \\
\hline Electron tail slope & $40 \times 10^{-3}$ & $\mathrm{eV}$ \\
\hline Hole tail slope & $60 \times 10^{-3}$ & $\mathrm{eV}$ \\
\hline Electron mobility & $2.48 \times 10^{-7}$ & $\mathrm{~m}^{2} \mathrm{~V}^{-1} \mathrm{~s}^{-1}$ \\
\hline Hole mobility & $2.48 \times 10^{-7}$ & $\mathrm{~m}^{2} \mathrm{~V}^{-1} \mathrm{~s}^{-1}$ \\
\hline Relative permittivity & 3.8 & $\mathrm{Au}$ \\
\hline Number of traps & 20 & $\mathrm{Bands}^{-2}$ \\
\hline $\begin{array}{l}\text { Free electron to trapped } \\
\text { Electron }\end{array}$ & $2.5 \times 10^{-20}$ & $\mathrm{~m}^{-2}$ \\
\hline $\begin{array}{l}\text { Trapped electron to free } \\
\text { Hole }\end{array}$ & $1.32 \times 10^{-22}$ & $\mathrm{~m}^{-2}$ \\
\hline $\begin{array}{l}\text { Trapped hole to free } \\
\text { electron }\end{array}$ & $4.67 \times 10^{-26}$ & $\mathrm{~m}^{-2}$ \\
\hline $\begin{array}{l}\text { Effective density of free } \\
\text { Electron states (300K) }\end{array}$ & $1.28 \times 10^{27}$ & $\mathrm{~m}^{-3}$ \\
\hline $\begin{array}{l}\text { Effective density of free } \\
\text { Hole states (300K) }\end{array}$ & $2.86 \times 10^{25}$ & $\mathrm{~m}^{-3}$ \\
\hline $\begin{array}{l}\text { Free hole to trapped hole } \\
\text { Photonic Energy gap (Eg) }\end{array}$ & $4.86 \times 10^{-26}$ & $\mathrm{~m}^{-2}$ \\
\hline
\end{tabular}

\section{Device Model Authentication}

GPVDM is 3-D modeling software that can build and analyze various kinds of solar cells and other optoelectronic devices such as OLEDs and OFETS. The correctness of the software has been proven by published research [12-16, 31-35]. It evaluated the performance of the device from actual experimental characterization to software-generated theoretical results. As an effect, it can verify the feasibility and accessibility of cell formation and material values to a certain extent.

\section{RESULTS AND DISCUSSIONS}

\section{A. Effect of Layer Thickness}

Different parameters can increase the productivity in organic solar cells (OSC); one of these is the layer thickness of a specific structure. In this research study, electrical stimulation has 
been done at different active layer thicknesses from $50 \mathrm{~nm}$ to $200 \mathrm{~nm}$ while keeping all other parameters the same.

Table.2, Fig. 3 and Fig. 4 show the aberration in the cell's performance with the thickness of the absorber layer. As shown in Fig. 4, the increase in efficiency by increasing thickness of absorber layer is due to a more significant number of photon absorption that produces more electron and hole pairs, which is separated by the electric field generated by the difference in the work function of blend layers and finally transported to electrode layers. When the active layer thickness surpasses the value of $100 \mathrm{~nm}$, efficiency (PCE) decreases due to the contribution of more excess carriers in the recombination. In Jsc vs thickness graph (Fig.3), it can be seen by increasing thickness, short-circuit current density (Jsc) rises and approaches to the optimum value of $\sim 135 \mathrm{Am}^{-2}$ due to more excess charge carriers. In Voc vs thickness graph (Fig.3), the increase in thickness causes a drop in opencircuit voltage due to the high recombination rate. While in the FF vs thickness graph (Fig.4), the fill factor degrades as the active layer thickness increases due to the escalation of internal power depletion.

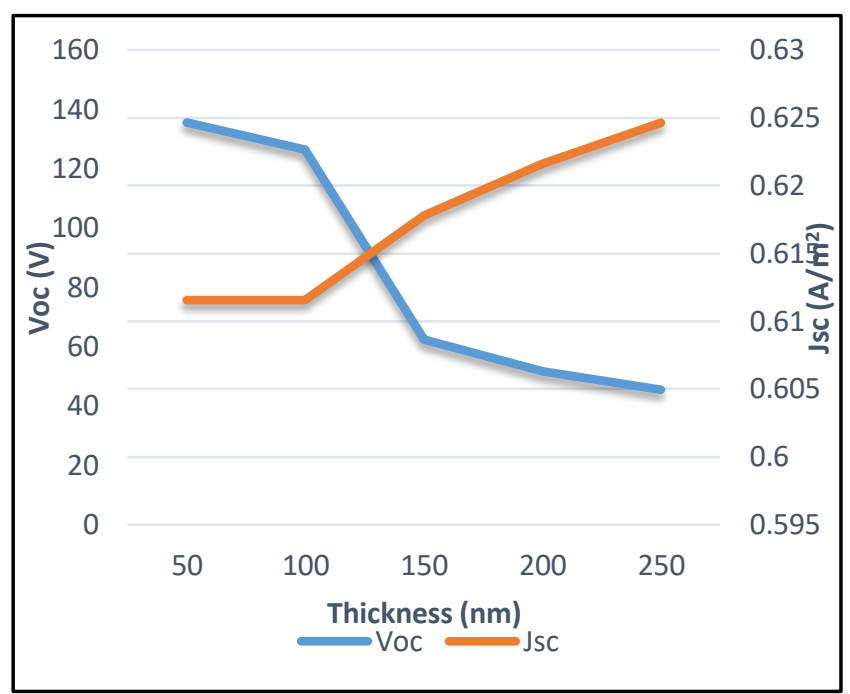

Fig. 3: Open-circuit voltage (Voc) and shortcircuit current density (Jsc) vs. Active layer thickness (nm)

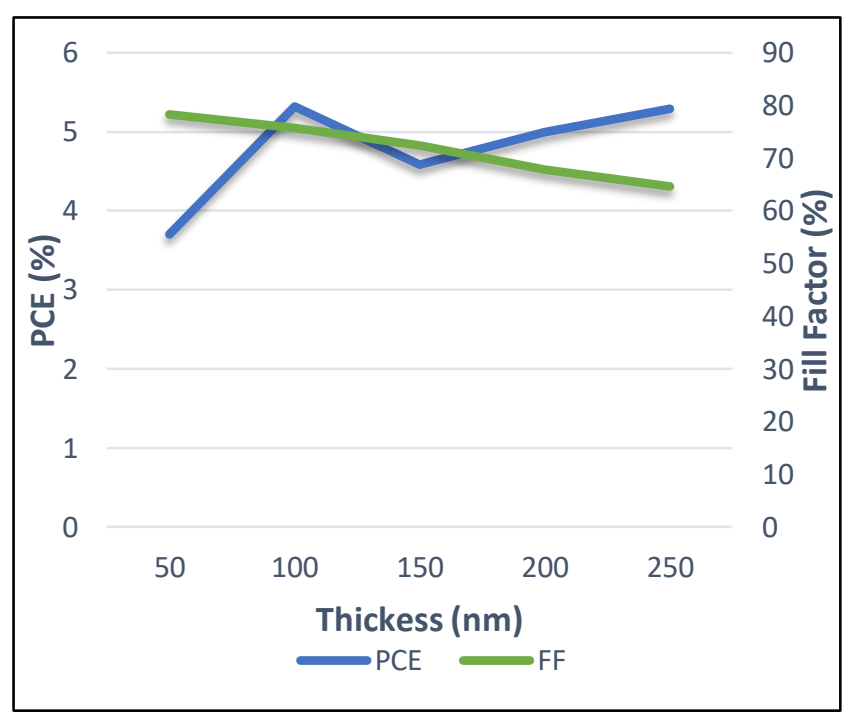

Fig. 4: PCE (\%) and FF (\%) vs. Active layer thickness $(\mathrm{nm})$

Table-2: Device Performance at a different absorber layer thickness

\begin{tabular}{|l|l|l|l|l|}
\hline Thickness (nm) & Voc (V) & Jsc (A/m $\left.\mathbf{m}^{2}\right)$ & FF (\%) & PCE (\%) \\
\hline 50 & 0.6246 & 75.70 & 78.29 & 3.7 \\
\hline 100 & 0.6227 & 75.70 & 75.74 & 5.32 \\
\hline 150 & 0.6086 & 104.12 & 72.33 & 4.58 \\
\hline 200 & 0.6063 & 121.65 & 67.77 & 4.99 \\
\hline 250 & 0.6050 & 135.46 & 64.62 & 5.30 \\
\hline
\end{tabular}




\section{B. Effect of charge carrier mobility}

The extraction and recombination of the charging carriers are two opposing processes in the organic solar cell; both are accomplished through the charging carrier's mobility. Increased carrier charged mobility would enhance extraction, but it would also increase bi-molecule recombination, as it would have a beneficial influence on charge carrier transport. As shown in Table.3, Fig.5 and Fig.6, charge carrier mobility was altered from $2.48 \times 10^{-7}$ to $2.48 \times 10^{-4}$ $\mathrm{m}^{2} / \mathrm{Vs}$ to explore the impact on device performance, and it was determined that the best PCE was attained at the mobility value of $2.48 \times 10^{-5} \mathrm{~m}^{2} / \mathrm{Vs}$. In the Voc vs Mobility graph (Fig.5), open-circuit voltage drops as carrier transport improve because of rising internal power depletion, which reduces the influence of a built-in electric field. When the mobility of carrier increases, due to better carrier transport at particular edges, short-circuit current density rises, resulting in high efficiency and fill factor. As carrier mobility decreases, short-circuit current density falls because of separation probability and bad transport of charge carriers, resulting in reduced energy conversion efficiency and fill factor, as shown in Fig.5 and Fig.6.

Table-3: Device performance at different carrier mobility

\begin{tabular}{|c|c|c|c|c|}
\hline Mobility (m²/Vs) & Voc (V) & $\operatorname{Jsc}\left(A / m^{2}\right)$ & FF (\%) & PCE (\%) \\
\hline $2.48 e-04$ & 0.5129 & 122.87 & 77.94 & 4.9118 \\
\hline $2.48 e-05$ & 0.5662 & 122.90 & 78.46 & 5.4578 \\
\hline $2.48 e-06$ & 0.5997 & 122.90 & 76.78 & 5.6522 \\
\hline $2.48 e-07$ & 0.6063 & 121.65 & 67.74 & 4.9992 \\
\hline
\end{tabular}

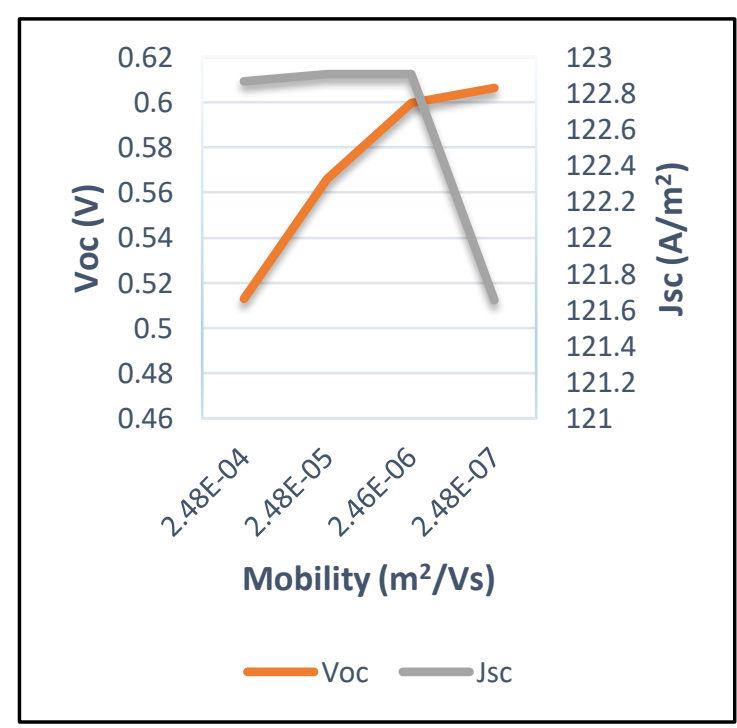

Fig. 5: Open circuit voltage (Voc) and short circuit current density (Jsc) vs Carrier Mobility $\left(\mathrm{m}^{2} / \mathrm{Vs}\right)$

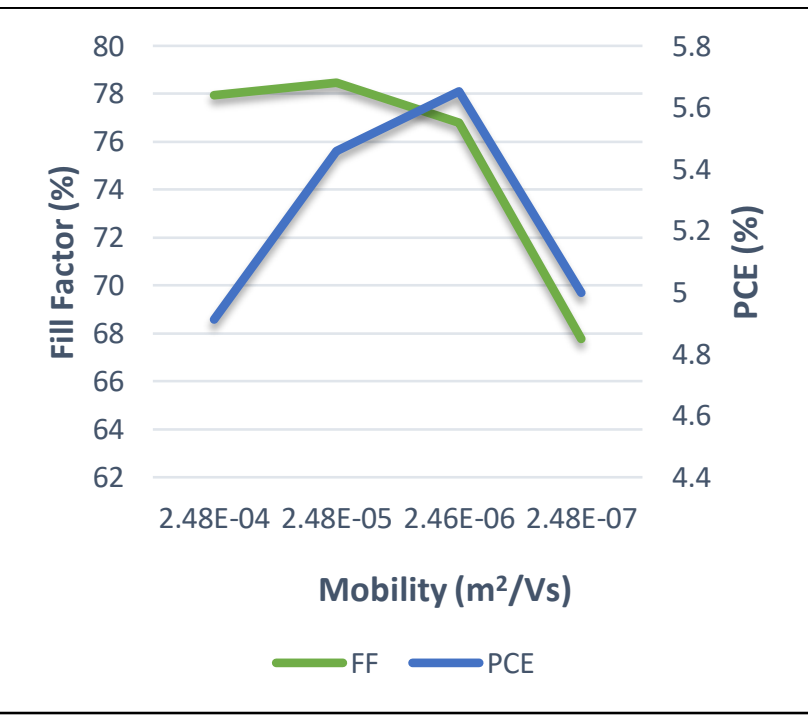

Fig. 6: PCE (\%) and FF (\%) vs Carrier Mobility $\left(\mathrm{m}^{2} / \mathrm{Vs}\right.$ 


\section{Comparison of different hole transport material}

As HTM plays essential part in achieving high efficiency and steadiness. PEDOT: PSS is extensively used HTM in various kinds of solar cells. There are many alternatives of PEDOT: PSS, but we have only used Spiro-MeOTAD and $\mathrm{Cu}_{2} \mathrm{O}$ here. The outcomes of these HTM are given in Table. 4 below. OSC with HTM PEDOT: PSS gives the power conversion efficiency (PCE) up to $6.25 \%$. Moreover, Spiro-MeOTAD exhibits a PCE of $6.83 \%$. But $\mathrm{Cu}_{2} \mathrm{O}$ gives better performance and high efficiency of nearly equal to 7\% among all HTMs as discussed above. It shows a superior outcome due to more vital interaction with the absorber layer. Due to its low cost, high relative stability, wide bandgap and high $\mathrm{p}$-type conductivity and, $\mathrm{Cu}_{2} \mathrm{O}$ has the ability to replace Spiro-MeOTAD in organic solar cells.

Table-4: Comparison of different HTM Layers

\begin{tabular}{|l|l|l|l|l|}
\hline HTM Layers & Voc (V) & Jsc (A/m $\left.\mathbf{m}^{\mathbf{2}}\right)$ & FF (\%) & PCE (\%) \\
\hline PEDOT:PSS & 0.5992 & 137.73 & 75.8964 & 6.2554 \\
\hline Spiro-MeOTAD & 0.6014 & 149.73 & 75.6598 & 6.8138 \\
\hline Cu2O & 0.6042 & 152.67 & 75.6891 & 6.9812 \\
\hline
\end{tabular}

\section{Optical Simulation Result of GPVDM}

GPVDM always performs an optical simulation even if the light intensity is not set to zero, and it will not dump it calculates to disk as this is too slow. Therefore, there is an optical window to explore the optical performance of the device in more detail. Fig.7 shows the peaks for the absorption of photons in each material. It is visible from the graph that the peak increases from $0 \mathrm{~nm}$ to $200 \mathrm{~nm}$ in which absorber material is positioned. The rise in Aluminum layers indicates that some amount of photon is also absorbed in the aluminum layer.

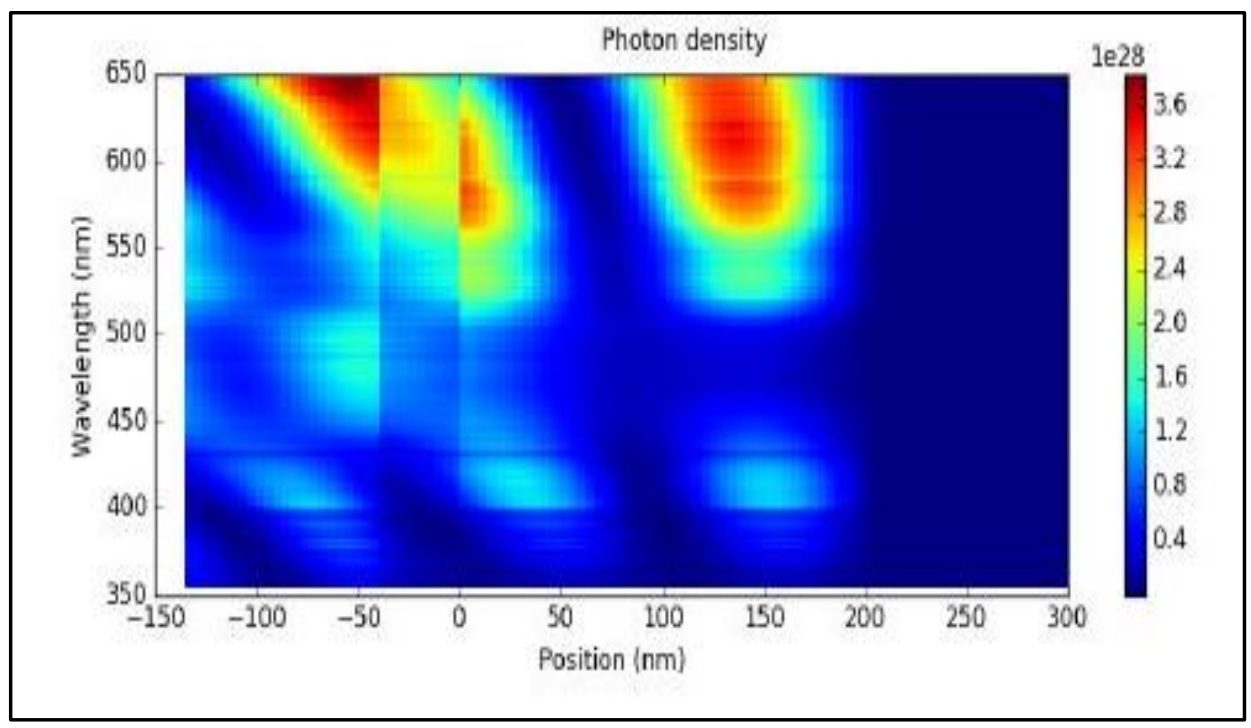

Fig. 7: Photon distribution-localization energy variance of investigated OSC 


\section{E. Comparison with Experimental Results}

The electrical simulations of organic solar cells are compared to some experimental results in the Table. 5. Experimental findings reported in the scientific literature are found to be close to simulated device performance characteristics. The results show that correct parameter selection, such as thickness, mobility, and proper HTM layer selection, contribute to high device power conversion efficiency, current density, and open-circuit voltage.

Table- 5: Comparison of Experimental Results with Simulated Results

\begin{tabular}{|l|l|l|l|l|}
\hline Experimental Result [36] & Jsc (mA/ cm $\left.\mathbf{~}^{\mathbf{}}\right)$ & Voc (V) & FF (\%) & PCE (\%) \\
\hline Polymer blend & 12.5 & 0.58 & 65.4 & 4.8 \\
\hline PTB1/PC60BM & 15.5 & 0.58 & 62.3 & 5.6 \\
\hline PTB1/PC70BM & 12.8 & 0.60 & 66.3 & 5.1 \\
\hline PTB2/PC60BM & 13.9 & 0.72 & 58.5 & 5.9 \\
\hline PTB3/PC60BM & 13.0 & 0.74 & 61.4 & 6.1 \\
\hline PTB4/PC60BM & 14.8 & 0.70 & 64.6 & 7.1 \\
\hline PTB4/PC70BM & 10.7 & 0.66 & 58.0 & 4.1 \\
\hline PTB5/PC60BM & 7.74 & 0.62 & 47.0 & 2.3 \\
\hline PTB6/PC60BM & 15.27 & 0.60 & 75.7 & 6.98 \\
\hline Simulated Result & \multicolumn{5}{|l|}{} \\
\hline PTB7/PC70BM & \multicolumn{5}{|l|}{} \\
\hline
\end{tabular}

\section{CONCLUSION}

The The organic solar cell is structured as ITO/PEDOT: PSS/PTB7:PC70BM/Al and designed by GPVDM. From the simulation, it is found that the output parameters \% PCE, \% FF, Voc, and Jsc at absorber layer thickness $250 \mathrm{~nm}$ and carrier mobility $2.46 \times 10^{-6} \mathrm{~m}^{2} / \mathrm{Vs}$ utilizing $\mathrm{Cu}_{2} \mathrm{O}$ as an HTM are $6.98 \%, 75.6 \%, 0.60 \mathrm{~V}$ and $15.27 \mathrm{~mA} / \mathrm{cm}^{2}$, which is also compared with the performance of the experimental organic solar cell. Furthermore, the effect of absorber layer thickness, carrier mobility, and hole transport material on device performance was studied. Absorber layer thickness optimization shows that $250 \mathrm{~nm}$ thickness for an organic solar cell is suitable for photovoltaic characteristics. And charge carrier mobility in this range delivers the best performance. This study also gives hypothetical direction towards the efficient realization of organic solar cells by adjusting their parameters on which the performance of the organic solar cell is highly dependent.

\section{ACKNOWLEDGMENT}

The authors are very thankful to Roderick C I MacKenzie for providing the free GPVDM simulation software for modeling and optimization.

\section{CONFLICTS OF INTEREST}

There are no financial issues or interest of conflicts to declare.

\section{REFERENCES}

[1] Hoppe, H., \& Sariciftci, N. S. (2004). Organic solar cells: An overview. Journal of materials research, 19(7), 1924-1945.

[2] Rastogi, N., Singh, N., \& Saxena, S. (2017). Analysis of Organic Photovoltaic Device at Different Series Resistances. vol, 5, 83-87. 
[3] Kearns, D., \& Calvin, M. (1958). Photovoltaic effect and photoconductivity in laminated organic systems. The Journal of chemical physics, 29(4), 950-951.

[4] Ghosh, A. K., Morel, D. L., Feng, T., Shaw, R. F., \& Rowe Jr, C. A. (1974). Photovoltaic and rectification properties of $\mathrm{Al} / \mathrm{Mg}$ phthalocyanine/Ag Schottky-barrier cells. Journal of Applied Physics, 45(1), 230-236.

[5] Weinberger, B. R., Akhtar, M., \& Gau, S. C. (1982). Polyacetylene photovoltaic devices. Synthetic Metals, 4(3), 187-197.

[6] Glenis, S., Tourillon, G., \& Garnier, F. (1986). Influence of the doping on the photovoltaic properties of thin films of poly-3-methylthiophene. Thin Solid Films, 139(3), 221-231.

[7] Sariciftci, N. S., Braun, D., Zhang, C., Srdanov, V. I., Heeger, A. J., Stucky, G., \& Wudl, F. (1993). Semiconducting polymer-buckminsterfullerene heterojunctions: Diodes, photodiodes, and photovoltaic cells. Applied physics letters, 62(6), 585-587.

[8] Halls, J. J., Pichler, K., Friend, R. H., Moratti, S. C., \& Holmes, A. B. (1996). Exciton diffusion and dissociation in a poly (p-phenylenevinylene)/C60 heterojunction photovoltaic cell. Applied Physics Letters, 68(22), 3120-3122.

[9] Halls, J. J. M., \& Friend, R. H. (1997). The photovoltaic effect in a poly (pphenylenevinylene)/perylene heterojunction. Synthetic metals, 85(1-3), 1307-1308.

[10] Sharma, S., Jain, K. K., \& Sharma, A. (2015). Solar cells: in research and applications-a review. Materials Sciences and Applications, 6(12), 1145.

[11] Zhang, H., Li, Y., Zhang, X., Zhang, Y., \& Zhou, H. (2020). Role of interface properties in organic solar cells: from substrate engineering to bulk-heterojunction interfacial morphology. Materials Chemistry Frontiers, 4(10), 2863-2880.

[12] Hima, A., Khechekhouche, A., Kemerchou, I., Lakhdar, N., Benhaoua, B., Rogti, F., ... \& Saadoun, A. (2018). GPVDM simulation of layer thickness effect on power conversion efficiency of $\mathrm{CH} 3 \mathrm{NH} 3 \mathrm{PbI} 3$ based planar heterojunction solar cell. International Journal of Energetica, 3(1), 37-41.

[13] Singh, N., Chaudhary, A., Saxena, S., Saxena, M., \& Rastogi, N. (2017). Electrical Simulation of Organic Solar Cell at Different Charge Carrier Mobility. IOSR J. Appl. Phys, 9(02), 01-04.

[14] Abdulsalam, H., Babaji, G., \& Abba, H. T. (2018). The Effect of Temperature and Active layer thickness on the Performance of CH3NH3PbI3 Perovskite Solar Cell: A Numerical Simulation Approach. Journal for Foundations and Applications of Physics, 5(2), 141-151.

[15] Talib, Y. Y. A. (2014). Optimization of pedot: PSS thin film for organic solar cell application (Doctoral dissertation, Universiti Tun Hussein Onn Malaysia).

[16] Rastogi, N., Singh, N., \& Saxena, S. (2017). Analysis of Organic Photovoltaic Device at Different Series Resistances. vol, 5, 83-87.

[17] Mostefaoui, M., Mazari, H., Khelifi, S., Bouraiou, A., \& Dabou, R. (2015). Simulation of high efficiency CIGS solar cells with SCAPS-1D software. Energy Procedia, 74, 736-744.

[18] Tan, K., Lin, P., Wang, G., Liu, Y., Xu, Z., \& Lin, Y. (2016). Controllable design of solidstate perovskite solar cells by SCAPS device simulation. Solid-State Electronics, 126, 75-80.

[19] Hussain, S. S., Riaz, S., Nowsherwan, G. A., Jahangir, K., Raza, A., Iqbal(2021). Numerical Modeling and Optimization of Lead-Free Hybrid, Journal of Renewable Energy, 2021.

[20] Dong, B., Bailey, C. G., Afanasev, A., \& Zaghloul, M. (2014, June). Modeling and simulation of InAs/GaAs quantum dot solar cells in SILVACO TCAD. In 2014 IEEE 40th Photovoltaic Specialist Conference (PVSC) (pp. 0476-0478). IEEE.

[21] Nayak, P. P., Dutta, J. P., \& Mishra, G. P. (2015). Efficient InGaP/GaAs DJ solar cell with double back surface field layer. Engineering Science and Technology, an International Journal, 18(3), 325-335. 
[22] Mohanty, S. P., Padhy, S., Chowdhury, J., \& Sing, U. P. (2018, May). Numerical investigation of optimized CZTSSe based solar cell in Wx-Amps environment. In AIP Conference Proceedings (Vol. 1966, No. 1, p. 020024). AIP Publishing LLC.

[23] Zandi, S., Saxena, P., \& Gorji, N. E. (2020). Numerical simulation of heat distribution in RGO-contacted perovskite solar cells using COMSOL. Solar Energy, 197, 105-110.

[24] Saxena, P., \& Gorji, N. E. (2019). COMSOL simulation of heat distribution in perovskite solar cells: coupled optical-electrical-thermal 3-D analysis. IEEE Journal of Photovoltaics, 9(6), 1693-1698.

[25] MacKenzie, R. C. (2016). GPVDM user manual.

[26] Park, S., Jeong, J., Hyun, G., Kim, M., Lee, H., \& Yi, Y. (2016). The origin of high PCE in PTB7 based photovoltaics: proper charge neutrality level and free energy of charge separation at PTB7/PC 71 BM interface. Scientific reports, 6(1), 1-11.

[27] Stelling, C., Singh, C. R., Karg, M., König, T. A., Thelakkat, M., \& Retsch, M. (2017). Plasmonic nanomeshes: their ambivalent role as transparent electrodes in organic solar cells. Scientific reports, 7(1), 1-13.

[28] Chen, C. W., Hsiao, S. Y., Chen, C. Y., Kang, H. W., Huang, Z. Y., \& Lin, H. W. (2015). Optical properties of organometal halide perovskite thin films and general device structure design rules for perovskite single and tandem solar cells. Journal of Materials Chemistry A, 3(17), 9152-9159.

[29] Edward, D. P., \& Palik, I. J. H. O. O. C. O. S. (1985). Handbook of optical constants of solids. Handbook of Optical Constants of Solids.

[30] Holman, Z. C., Filipič, M., Descoeudres, A., De Wolf, S., Smole, F., Topič, M., \& Ballif, C. (2013). Infrared light management in high-efficiency silicon heterojunction and rearpassivated solar cells. Journal of Applied Physics, 113(1), 013107.

[31] MacKenzie, R. C. I., Balderrama, V. S., Schmeisser, S., Stoof, R., Greedy, S., Pallarès, J., ... \& Von Hauff, E. (2016). Loss mechanisms in high efficiency polymer solar cells. Advanced Energy Materials, 6(4), 1501742.

[32] Gao, Y., MacKenzie, R. C., Liu, Y., Xu, B., Van Loosdrecht, P. H., \& Tian, W. (2015). Engineering ultra-long charge carrier lifetimes in organic electronic devices at room temperature. Advanced Materials Interfaces, 2(4), 1400555.

[33] Liu, Y., MacKenzie, R. C., Xu, B., Gao, Y., Gimeno-Fabra, M., Grant, D., ... \& Tian, W. (2015). Organic semiconductors with a charge carrier lifetime of over 2 hours at room temperature. Journal of Materials Chemistry C, 3(47), 12260-12266.

[34] Sims, L., Hörmann, U., Hanfland, R., MacKenzie, R. C., Kogler, F. R., Steim, R., .. \& Schilinsky, P. (2014). Investigation of the s-shape caused by the hole selective layer in bulk heterojunction solar cells. Organic Electronics, 15(11), 2862-2867.

[35] Hanfland, R., Fischer, M. A., Brütting, W., Würfel, U., \& MacKenzie, R. C. (2013). The physical meaning of charge extraction by linearly increasing voltage transients from organic solar cells. Applied Physics Letters, 103(6), 063904.

[36] Lu, L., \& Yu, L. (2014). Understanding low bandgap polymer PTB7 and optimizing polymer solar cells based on it. Advanced Materials, 26(26), 4413-4430.

(C) 2021 by the author. Licensee ICRRD, Kuala Lumpur, Malaysia. This article is an open access article distributed under the terms and conditions of the Creative Commons Attribution(CC BY) license (http://creativecommons.org/licenses/by/4.0/). 